\title{
Note on Transliteration*
}

1. I distinguish long vowels from short vowels with an accent over the appropriate roman letter.
a (as in 'about') á (as in ' $a \mathrm{rt}$ ')
$\mathrm{i}$ (as in 'ink') í (as in 'eel')
$\mathrm{u}$ (as in 'put') ú (as in 'pool')
e (as in ' $e$ nd') é (as in ' $a$ le')
$\mathrm{o}$ (as in 'box') ó (as in 'bowl')

2. I distinguish long or stressed consonants from short or unstressed consonants by doubling the appropriate roman letter.

3. I distinguish retroflexes from dentals by underlining the particular letter, either $\underline{\mathrm{t}} \underline{\mathrm{n}}, \underline{\mathrm{l}}$, or $\underline{\mathrm{r}}$. Also, since retroflex $\underline{\mathrm{r}}$ and $\underline{\mathrm{l}}$ are often interchangeable, I opt for $\underline{l}$ as it is more common in practice. Hence, I write Tamil or ulaippu.

4. The sounds $s$ and ch are represented by c.

5. I sometimes distinguish voiced sounds-b, d, j, g-from the corresponding sounds of $\mathrm{p}, \mathrm{t}, \mathrm{cc}$, or $\mathrm{k} / \mathrm{h}$, although the Tamil letters are the same and the rules for voice sounds are based on placement. The voiced sounds b, $\mathrm{d}, \mathrm{j}$, g follow nasals; and $\mathrm{p}, \mathrm{t}$ and $\mathrm{t}$ are voiced between vowels; $\mathrm{k}$ is pronounced $\mathrm{h}$ or $\mathrm{g}$.

\footnotetext{
* I have drawn from E. Valentine Daniel's (1984) method of transliteration.
} 